\title{
Acute stimulation effect of the ventral capsule/ ventral striatum in patients with refractory obsessive-compulsive disorder - a double-blinded trial
}

\author{
This article was published in the following Dove Press journal: \\ Neuropsychiatric Disease and Treatment \\ 6 January 2014 \\ Number of times this article has been viewed
}

\author{
Hsin-Chi Tsai ${ }^{1,2}$ \\ Chun-Hung Chang ${ }^{3,4}$ \\ Jiann-I Pan ${ }^{5}$ \\ Hung-Jen Hsieh ${ }^{6}$ \\ Sheng-Tzung Tsai ${ }^{7}$ \\ Hsiang-Yi Hung ${ }^{7}$ \\ Shin-Yuan Chen ${ }^{1,7}$ \\ 'Institute of Medical Science, Tzu- \\ Chi University, Hualien City, Taiwan; \\ ${ }^{2}$ Department of Psychiatry, Tzu-Chi \\ General Hospital, Hualien City, \\ Taiwan; ${ }^{3}$ Department of Psychiatry, \\ China Medical University and \\ Hospital, Taichung, Taiwan; ${ }^{4} \mathrm{China}$ \\ Medical University, Taichung, Taiwan; \\ ${ }^{5}$ Department of Medical Informatics, \\ Tzu-Chi University, Hualien, Taiwan; \\ ${ }^{6}$ Nuclear Medicine, Tzu Chi General \\ Hospital, Hualien City, Taiwan; \\ ${ }^{7}$ Department of Neurosurgery, \\ Tzu-Chi General Hospital, \\ Hualien City, Taiwan
}

\begin{abstract}
Objective: Deep-brain stimulation (DBS) for treating refractory obsessive-compulsive disorder (OCD) has shown positive results in small clinical trials. Ventral capsule/ventral striatum (VC/ VS) is one of the promising targets; however, whether or not acute stimulation test can provide substantial information for chronic stimulation is not yet known. We evaluated postoperative test stimulation and examined the relationship of acute simulation-induced smile/laughter and 15-month clinical outcome.
\end{abstract}

Methods: Four adult patients with refractory OCD were implanted with Model 3387 leads bilaterally in an area of VC/VS. Postoperative test stimulation was performed at least 2 weeks after surgery. We performed double-blinded postoperative test stimulation with different contact and voltage. The relationship of stimulation-induced smile/laughter and chronic response was examined.

Results: Patients presented smile, laughter, euphoria, increased heart rate, increased blood pressure, smell, chest vibration, dizziness, nausea, heat, or increased sexual drive during acute stimulation. We found that the higher the percentage of smile/laughter $(34.3 \%, 31.3 \%, 56.3 \%$, and $12.5 \%$ for four cases), the greater the reduction in the Yale-Brown Obsessive Compulsive Scale $(30.6 \%, 38.9 \%, 58.8 \%$, and $7.7 \%$ respectively at 15 -month DBS).

Conclusion: This study showed that acute DBS of the VC/VS might cause mood change, cardiovascular, sensory, or motor effects. These effects were transient or habituated over six months. We suggest stimulation-induced smile/laughter may be a possible predictor for longterm DBS outcome. Larger studies, genetic studies, and imaging studies are needed to evaluate the effects of different parameters and possible predictors in the treatment of OCD.

Keywords: deep-brain stimulation, DBS, OCD, VC/VS, nucleus accumbens, NAcc

\section{Introduction}

Obsessive-compulsive disorder (OCD) is characterized by intrusive thoughts or images (obsessions), and by repetitive or ritualistic actions (compulsions). ${ }^{1}$ The lifetime prevalence of OCD is approximately $2 \% .^{2}$ Pharmacological and cognitive behavioral treatments remain as the mainstay to alleviate symptoms; however, $25 \%-40 \%$ of patients do not have a satisfactory outcome. ${ }^{3}$ Deep-brain stimulation (DBS) is now being extended to treatment of neuropsychiatric conditions such as Gilles de la Tourette syndrome, OCD, depression, and addiction. ${ }^{4}$ Small-scale use in controlled ${ }^{5-11}$ or open studies ${ }^{12-15}$ has suggested therapeutic promise. In all research groups, at least $50 \%$ of previously refractory patients exhibited improvement within a year in terms of partial response
Correspondence: Shin-Yuan Chen Institute of Medical Science, Tzu-Chi University, Department of Neurosurgery, Tzu-Chi General Hospital, No 707,

Sec 3, Chung Yang Rd,

Hualien 970, Taiwan

$\mathrm{Tel}+886038561825$

Fax +886038574049

Email b89401068@ntu.edu.tw
Neuropsychiatric Disease and Treatment 2014:10 63-69 
(improvement of $\geq 25 \%$ on the Yale-Brown Obsessive Compulsive Scale [YBOCS]). ${ }^{16}$ Intraoperative or postoperative acute stimulation at any given contact is used primarily in evaluating effects and determining which electrode configurations to use for chronic stimulation. ${ }^{17}$ However, whether or not acute stimulation test can provide substantial information for chronic stimulation is not yet known. Haq et al reported that acute stimulation-induced laughter may predict longterm OCD response to DBS. Identifying potential response predictors for OCD will become increasingly important as more patients are implanted with DBS devices. ${ }^{18}$ In this study, we evaluated postoperative test stimulation and examined the relationship of acute simulation-induced smile/laughter and 15-month clinical outcome.

\section{Methods and materials}

\section{Patients}

Four adults who met the criteria of the Diagnostic Statistical Manual of Psychiatric Disorders fourth edition (DSM-IV) for OCD and underwent ventral capsule/ventral striatum (VC/VS) DBS were enrolled for this study (Table 1). Subjects must have had at least a 5-year history of treatmentrefractory OCD symptoms, and the disorder must have caused substantial suffering as well as a reduction in the subject's functioning. Treatment resistance was defined as failure to obtain improvements following multiple trials of pharmacotherapy at maximally tolerated doses, and one or more adequate trials of cognitive behavioral therapy. Our patients met the requirement of level VII in this trial. ${ }^{19}$ Details of inclusion/exclusion criteria for DBS have been described in our previous study. ${ }^{20}$

\section{Surgical procedure}

The study was approved by the Institutional Review Boards (IRBs) of the Buddhist Tzu-Chi General Hospital, Taiwan (IRB094-33). After the patients had discussed with their families and signed informed consent, we implanted Model 3387 leads bilaterally in an area spanning the ventral anterior limb of the internal capsule and adjacent ventral striatum, referred to as the VC/VS. A high resolution, T1-weighted image (T1WI) with $0.7 \mathrm{~mm}$ slice thickness was obtained 1 day before the surgery using a $1.5 \mathrm{~T}$ magnetic resonance imaging (MRI) scanner (General Electric, Milwaukee, WI, USA). We used a Leksell Stereotactic System ${ }^{\circledR}$ (Elekta, Stockholm, Sweden) under local anesthesia. A high-resolution head computed tomography (CT) scan with a slice thickness of $1.25 \mathrm{~mm}$ was performed. The images were transferred to a neuro-navigation workstation (VectorVision; Brainlab, Feldbirchen, Germany/StealthStation; Medtronic, Minneapolis, MN, USA), and then the MRI and CT-based images were fused. Electrodes were implanted according to a set of anatomical landmarks - anterior commissure $(\mathrm{AC})$ and posterior commissure (PC), AC-PC plane, and the anterior limb of the internal capsule - using the Leksell Stereotactic System under general anesthesia. Each lead was $1.27 \mathrm{~mm}$ in diameter with four $1.5 \mathrm{~mm}$ long electrode contacts, separated from adjacent contacts by a distance of $1.5 \mathrm{~mm}$. The contacts were at the tip of the lead and numbered from 0 (deepest) to 3 (most superficial) (Table 2).

\section{Postoperative test stimulation}

To reduce operation duration, risk, patients' discomfort, and to avoid anesthesia effects, we did not perform intraoperative test stimulation. Postoperative test stimulation was performed at least 2 weeks after the DBS surgery. The patient sat comfortably in a chair and was continuously videotaped during each testing. In accordance with stimulation settings employed by other groups, ${ }^{5,6,11}$ we fixed the pulse width at $210 \mu \mathrm{s}$, the stimulation frequency at $130 \mathrm{~Hz}$, and used a monopolar mode. A test condition was defined as the application of a particular voltage at a particular contact. Each contact $(0,1,2$, and 3$)$ of the lead was stimulated postoperatively at increasing voltages $(0,2,4,6$, and $8 \mathrm{~V})$ and turned to zero between each, giving a total of 16 possible

Table I Patient characteristics and lead locations

\begin{tabular}{|c|c|c|c|c|c|}
\hline Patient & $\begin{array}{l}\text { Age at surgery } \\
\text { (years), sex }\end{array}$ & $\begin{array}{l}\text { OCD onset } \\
\text { (years) }\end{array}$ & $\begin{array}{l}\text { OCD duration } \\
\text { (years) }\end{array}$ & $\begin{array}{l}\text { Baseline } \\
\text { YBOCS }\end{array}$ & Primary symptoms \\
\hline Case I & $30, M$ & $1 \mathrm{II}$ & 9 & 36 & Fear of contamination, hand-washing \\
\hline Case 2 & $30, M$ & 16 & 11 & 36 & $\begin{array}{l}\text { Symmetrically checking his teeth, } \\
\text { sexual thoughts, and ritualized } \\
\text { bathing }\end{array}$ \\
\hline Case 3 & $2 I, M$ & 15 & 5 & 34 & $\begin{array}{l}\text { Fear of erotic images, beating his } \\
\text { scrotum or eyeballs }\end{array}$ \\
\hline Case 4 & $2 \mathrm{I}, \mathrm{M}$ & 10 & 8 & 39 & $\begin{array}{l}\text { The fear of contamination, fear of } \\
\text { death, hand-washing, spitting }\end{array}$ \\
\hline
\end{tabular}

Abbreviations: OCD, obsessive-compulsive disorder; YBOCS, Yale-Brown Obsessive Compulsive Scale; M, male. 
Table 2 Results of left-side VC/VS DBS testing with the pulse width at $210 \mu$ s and the frequency at $130 \mathrm{~Hz}$

\begin{tabular}{|c|c|c|c|c|c|c|c|}
\hline $\begin{array}{l}\text { Left-side } \\
\text { Case number }\end{array}$ & $\begin{array}{l}\text { Length } \\
\text { of } A C-P C \\
\text { line }(\mathrm{mm})\end{array}$ & Contact & $\mathbf{x}$ & y & $\mathbf{z}$ & $\begin{array}{l}\text { Response } \\
\text { Smile/laughter } \\
\text { Min V }\end{array}$ & $\begin{array}{l}\text { Patient } \\
\text { comments }\end{array}$ \\
\hline \multirow[t]{4}{*}{ I } & 24.7 & 0 & -6.7 & 15.5 & -4.9 & 6 & $\begin{array}{l}\text { Smell at } 6 \text { and } 8 \mathrm{~V} \text {, chest tightness } \\
\text { at } 6 \text { and } 8 \mathrm{~V}\end{array}$ \\
\hline & & I & -7.9 & 16.7 & -2.0 & 6 & $\begin{array}{l}\text { Smell at } 4-8 \mathrm{~V} \text {, chest tightness at } \\
4-8 \mathrm{~V} \text {, increased sexual drive at } \\
6-8 \mathrm{~V} \text {, poor attention and memory, } \\
\text { mouth numbness at } 8 \mathrm{~V}\end{array}$ \\
\hline & & 2 & -9.6 & 17.5 & -0.1 & 6 & $\begin{array}{l}\text { Smell at } 6-8 \mathrm{~V} \text {, chest tightness at } \\
4-8 \mathrm{~V} \text {, increased sexual drive at } \\
6-8 \mathrm{~V} \text {, poor attention and memory, } \\
\text { sweating at } 8 \mathrm{~V}\end{array}$ \\
\hline & & 3 & -11.1 & 18.9 & 3.0 & - & Smell at 4-6 V, sweating at $8 \mathrm{~V}$ \\
\hline \multirow[t]{4}{*}{2} & 28 & 0 & -8.6 & 18.3 & -4.9 & 6 & - \\
\hline & & 1 & -10.1 & 19.5 & -2.2 & 4 & - \\
\hline & & 2 & -11.9 & 20.2 & 0.6 & 6 & $\begin{array}{l}\text { Chest tightness at } 4 \mathrm{~V} \text {, palpitation } \\
\text { at } 6 \mathrm{~V} \text {, fear and nervousness at } 8 \mathrm{~V}\end{array}$ \\
\hline & & 3 & -13.6 & 20.7 & 3.4 & - & $\begin{array}{l}\text { Heat and palpitation at } 4 \mathrm{~V} \text {, sexual } \\
\text { drive at } 8 \mathrm{~V}\end{array}$ \\
\hline \multirow[t]{4}{*}{3} & 24.4 & 0 & -7.1 & 13.4 & -2.3 & 6 & $\begin{array}{l}\text { Smell at } 8 \mathrm{~V} \text {, dizziness at } 4 \text { and } 8 \mathrm{~V} \text {, } \\
\text { nausea at } 4 \mathrm{~V} \text {, chest vibration at } \\
6-8 \mathrm{~V} \text {, heat at } 6 \mathrm{~V}\end{array}$ \\
\hline & & 1 & -8.4 & 14.6 & 0.4 & 4 & $\begin{array}{l}\text { Smell at } 4-8 \mathrm{~V} \text {, dizziness at } 6-8 \mathrm{~V} \text {, } \\
\text { chest vibration at } 6-8 \mathrm{~V} \text {, heat at } 8 \mathrm{~V}\end{array}$ \\
\hline & & 2 & -10.4 & 15.8 & 3 & 4 & $\begin{array}{l}\text { Dizziness at } 2-4 \mathrm{~V} \text {, nausea at } 4 \mathrm{~V} \text {, } \\
\text { chest vibration at } 4-8 \mathrm{~V}\end{array}$ \\
\hline & & 3 & -12.5 & 16.8 & 5.7 & 4 & $\begin{array}{l}\text { Smell at } 2 \mathrm{~V} \text {, dizziness at } 2-4 \mathrm{~V} \text {, } \\
\text { chest vibration at } 8 \mathrm{~V}\end{array}$ \\
\hline \multirow[t]{4}{*}{4} & 27 & 0 & -7.2 & 14.9 & -2.4 & 8 & - \\
\hline & & 1 & -7.6 & 16 & 0.6 & 8 & Dizziness at $8 \mathrm{~V}$ \\
\hline & & 2 & -9.3 & 16.8 & 3.7 & - & - \\
\hline & & 3 & -11.3 & 17.8 & 6.8 & - & Nausea at $6 \mathrm{~V}$, dizziness at $8 \mathrm{~V}$ \\
\hline
\end{tabular}

Notes: $\mathrm{x}=$ lateral, $\mathrm{y}=$ anteroposterior, $\mathrm{z}=$ axial. Stimulation-induced effects were observed fewer and weaker at right-sided locations than at left-sided locations. Abbreviations: AC-PC, anterior commissure-posterior commissure; DBS, deep-brain stimulation; VC/VS, ventral capsule/ventral striatum; Min, minimum.

tests. After completing testing of the left electrode, we tested the right electrode. One psychiatrist adjusted parameter settings according to the prepared flowchart; for example, contact $0,2,1,3$, or 3, 2, 1, 0 in a specific order. The patients knew that they were going to receive testing, but were not aware of the settings. Another psychiatrist who evaluated the patient's response was also blind to the parameter settings. One camera was used to record their verbal and behavioral response.

Smile means "a slow, gentle, sideward and upward pull of mouth, without rhythmical movements or contraction of other facial muscles," and laughter is smile accompanied by vocal sounds. ${ }^{21}$ But it is difficult to distinguish smile from laughter because of low-volume sounds, or rapid progress from smile to laughter. We recorded smile/laughter when the patient showed smile or laughter by the rater at the time of their occurrence. We also rated mood change (euphoria) according to a ten-point Likert scale on per contact and voltage (percentage induced smile/laughter $=[\mathrm{smile} /$ laughter conditions]/total tested conditions). Systolic blood pressure (SBP), diastolic blood pressure (DBP), and heart rate (HR) were recorded during each setting. We performed the test for about 1 hour and then turned off the device.

\section{Chronic DBS outcome measures}

Psychiatric evaluations were conducted preoperatively, postoperatively, and at follow-up visits every 3 months. We did not adjust settings every 3 months. The primary efficacy endpoint of this study was the mean change of YBOCS score from baseline. We used the Hamilton Depression Rating Scale (HAM-D) for depression, and Wechsler Adult Intelligence Scale III (WAIS-III) for cognitive functioning evaluation. Case 1 developed an allergy to right-side battery, which was then removed at 16 months. Therefore, 
we selected 15 months as an evaluation point. Statistical analyses were performed using SPSS 15.0 statistics software (IBM Corporation, Armonk, NY, USA).

\section{Results}

Table 2 shows the results of left-side VC/VS DBS testing. Case 1 reported smile/laughter with euphoria on contact 0 ( 6 and $8 \mathrm{~V}$ ), contact 1 (6 and $8 \mathrm{~V})$, but smile/laughter without euphoria on contact 2 ( 6 and $8 \mathrm{~V}$ ). Case 2 revealed smile/ laughter with euphoria on contact 0 ( 6 and $8 \mathrm{~V})$, contact 1 (4, 6 , and $8 \mathrm{~V})$, and contact 2 ( 6 and $8 \mathrm{~V})$; case 3 on contact 0 (6 and $8 \mathrm{~V})$, contact $1(4,6$, and $8 \mathrm{~V})$, contact 2 (6 and $8 \mathrm{~V})$, and contact $3(4,6$, and $8 \mathrm{~V})$; and case 4 on contact $0(8 \mathrm{~V})$, and contact $1(8 \mathrm{~V})$. All subjects experienced a sense of euphoria when the ventral contacts 0 and 1 with higher voltage were stimulated (contact 0 with voltage $0,2,4,6$, and $8 \mathrm{~V}$ : mean euphoria $0.0,0.0,1.5,2.5$, and 3.0 points; contact 1 with voltage $0,2,4,6$, and $8 \mathrm{~V}$ : mean euphoria $0.00,0.00$, $3.00,4.25$, and 5.25 points). Figure 1 shows that euphoria increased with voltage.

Case 1 felt chest tightness on eight settings, while case 2 felt palpitation on contact $2(6 \mathrm{~V})$ and contact $3(4 \mathrm{~V})$. The HR was significantly higher during the period of the active stimulation at $4 \mathrm{~V}$ than off stimulation period (mean score, $105.00 \pm 6.58$ versus $94.00 \pm 5.29 ; P<0.05)$. The SBP and DBP increased at higher voltage $4 \mathrm{~V}$ stimulation respectively, but not significantly.

During acute stimulation testing, we also observed smell, chest vibration, dizziness, nausea, heat, or increased sexual drive (Table 2). These feelings were transient or continuous with the stimulator on the "on" setting, and they immediately dissipated when switched off. Stimulationinduced effects were observed to be fewer and weaker at right-sided locations than at left-sided locations. Smile or laughter was reproducible when stimulated with the same contact and voltage. However, these responses habituated over several months and agreed with the findings of Springer et al. ${ }^{22}$

Before DBS surgery, the YBOCS score was $36.3 \pm 2.1$ at baseline. At the end of the 15 months follow-up, there was a $33.06 \%$ decrease in OCD severity (YBOC score 24.3 \pm 9.1 , $P=0.001)$. Baseline HAM-D score was 36.3 \pm 6.3 . After the 15-month follow-up, a $32.51 \%$ decrease in severity of depression was found (HAM-D score $=24.5 \pm 11.1, P=0.005$ ). Case 1 received neuropsychological assessment at baseline and 12 months after DBS surgery. WAIS full-scale intelligence quotient showed 106 at baseline and 102 at 12-month follow-up (Table 3).

\section{Discussion}

To our knowledge, our study is the first one to evaluate postoperative stimulation to predict long-term improvement. In this study, smile or laughter with euphoria was noted when the ventral contact 0 or 1 with higher voltage $(4,6$, and $8 \mathrm{~V}$ ) was tested. Okun et al found euphoria, smile, and laughter when the patient was tested at 4-8 V, bipolar mode, $130 \mathrm{~Hz}$, and pulse width $210 \mu \mathrm{s} .^{23}$ Improvement in mood and anxiety was commonly noted at ventral contacts by Greenberg et al with parameter setting (monopolar mode, $130 \mathrm{~Hz}$, pulse widths of 90 and $210 \mathrm{~ms}$ and at 2-6 V). ${ }^{11}$

Why did DBS in patients with refractory OCD cause these mood effects? One of the possible mechanisms is the
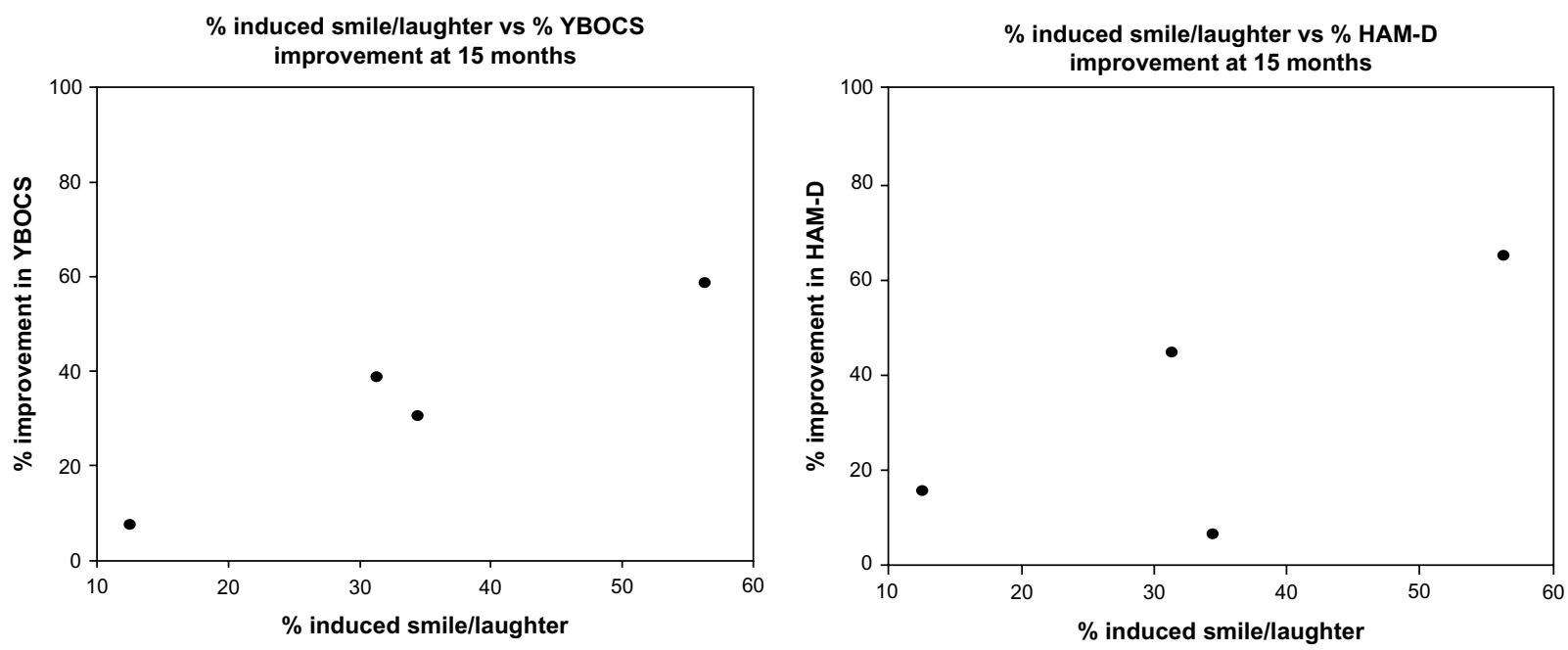

Figure I Clinical outcomes at 15 months versus (vs) percentage of smile/laughter conditions of postoperative test stimulation. Abbreviations: HAM-D, Hamilton Depression Rating Scale; YBOCS, Yale-Brown Obsessive Compulsive Scale. 
Table 3 Changes in the severity of OCD, depression, and cognition after 15 months of VC/VS DBS

\begin{tabular}{llllc}
\hline Variable & $\begin{array}{l}\text { Baseline } \\
\text { Mean } \pm \text { SD }\end{array}$ & $\begin{array}{l}\text { After I5 months of stimulation } \\
\text { Mean } \pm \text { SD }\end{array}$ & $\begin{array}{l}\text { Percentage } \\
\text { improvement }\end{array}$ & $\begin{array}{l}\text { P-value } \\
\text { YBOCS total score }\end{array}$ \\
\hline HAM-D score & $36.3 \pm 2.1$ & $24.3 \pm 9.1$ & $33.06 \%$ & $0.00 I$ \\
WAIS-III FIQ & $36.3 \pm 6.3$ & $24.5 \pm I I . I$ & $32.51 \%$ & 0.005 \\
\hline
\end{tabular}

Note: a Case I received neuropsychological assessment at baseline and 12 months after DBS surgery.

Abbreviations: DBS, deep-brain stimulation; FIQ, full-scale intelligence quotient; HAM-D, Hamilton Depression Rating Scale; OCD, obsessive-compulsive disorder; SD, standard deviation; VC/VS, ventral capsule/ventral striatum; WAIS-III, Wechsler Adult Intelligence Scale III; YBOCS, Yale-Brown Obsessive Compulsive Scale.

brain region of stimulation. Since our target, the $\mathrm{VC} / \mathrm{VS}$, is involved in complex brain circuits such as limbic circuits, ${ }^{24}$ this stimulation resulted in emotional effects. Furthermore, the ventral contact 0,1 was close to the nucleus accumbens, which is included in the mesolimbic dopamine system for pleasure and reward. ${ }^{25}$

Haq et al conducted intraoperative DBS testing for six patients at the anterior limb of the internal capsule and the nucleus accumbens region. ${ }^{18}$ They found that the higher the percentage of laugh conditions experienced in an individual patient, the greater the reduction in YBOCS. ${ }^{18}$ The percentage of laugh conditions for four cases was $34.4 \%$, $31.3 \%, 56.3 \%$, and $12.5 \%$. After the 15 -month follow-up, the improvement of the YBOCS score was $30.56 \%, 38.89 \%$, $58.82 \%$, and $7.69 \%$, respectively. The improvement of the HAM-D score was $6.67 \%, 44.44 \%, 64.71 \%$, and $15.56 \%$, respectively. Therefore, our finding agreed with Haq's group. The larger the percentage of laugh conditions for individual patients, the greater the percentage of reduction in YBOCS at the 15-month follow-up, although this was not significant (Spearman's rho $=0.80, P=0.10$ ) (Figure 2).

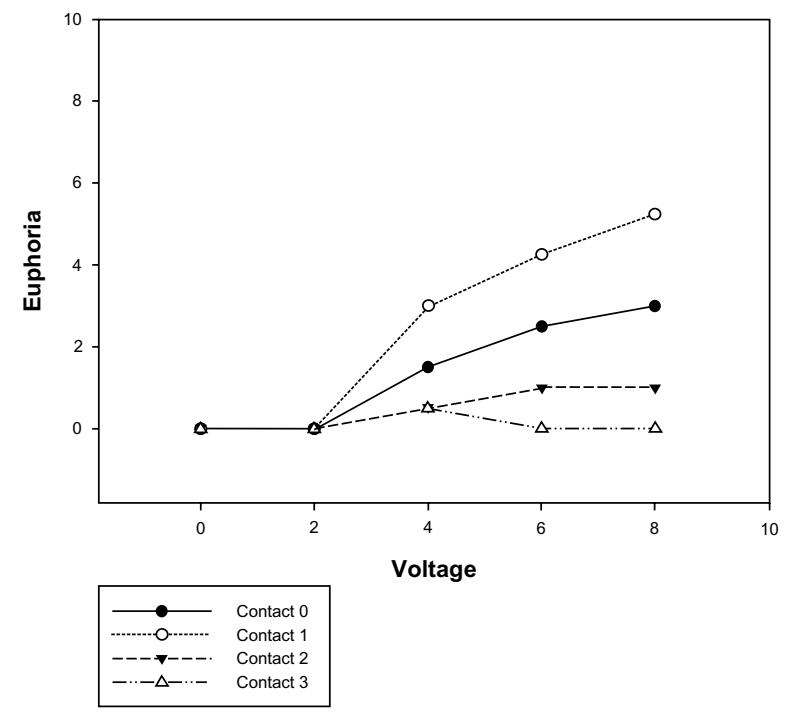

Figure 2 Postoperative test stimulation-induced mood change (euphoria) by lead contact and voltage.
Furthermore, Haq et al ${ }^{18}$ looked solely at bipolar intraoperative stimulation as a predictive response and did not explicitly establish that postoperative stimulation predicted long-term improvement. We evaluated the unipolar postoperative stimulation to predict long-term improvement. We also noted unilateral smiles were easier to induce than bilateral smiles, and that bilateral smiles were easier to induce than laughter.

In this study, increased SBP, DBP, and HR were observed after switching on the DBS at higher voltage. Shapira et $\mathrm{al}^{26}$ reported that intraoperative DBS on contact 0 , pulse width $210 \mathrm{~ms}$, rate $135 \mathrm{~Hz}$, at $6 \mathrm{~V}$ elicited a panic attack (only seen at the [0] contact). HR increased from $53 \mathrm{bpm}$ to $111 \mathrm{bpm}$. The effect was noted immediately after turning the device on, and abruptly ceased in the off condition. ${ }^{26}$ They suggest panic and increased HR may result from activation of limbic and autonomic networks. One scientific work described hypertension (160/120 $\mathrm{mmHg}$ ) during the DBS implantation of one cluster headache patient. ${ }^{27}$ But no autonomic effects were reported by Franzini et $\mathrm{al}^{28}$ and Vigneri et a ${ }^{29}$ in patients undergoing intraoperative DBS of the posterior hypothalamic area. One of the possible mechanisms is that the $\mathrm{VC} / \mathrm{VS}$ is also involved in autonomic circuit; ${ }^{30}$ this stimulation resulted in increased HR and blood pressure. However, further studies are necessary for specific targets and different parameters.

In this postoperative DBS testing, we also observed smell, chest vibration, dizziness, nausea, heat, or increased sexual drive. Sensory and motor effects may be related to the cortico-striatal-pallido-thalamocortical loop, ${ }^{30}$ while increased sexual drive is related to the medial preoptic area, which is involved in sexual arousal mechanisms and the expression of male sexual behavior. ${ }^{31}$ These feelings were transient or immediately dissipated when switched off.

This study has three limitations. First, the sample size was too small for adequate comparison. Second, we could not exclude the effects of medications and premorbid depression. Third, higher voltage may spread to surrounding structures which partially overlap with the circuitry responsible for post-DBS OCD improvement. 


\section{Conclusion}

Taken together, acute DBS of the VC/VS might cause smile, laughter, euphoria, increased blood pressure and HR, smell, chest vibration, dizziness, nausea, heat, or increased sexual drive. These effects are transient, disappearing when turned off, or habituated over months. Our results also suggest that postoperative stimulation-induced smile/laughter may predict long-term OCD response to DBS, and agree with Haq et al's intraoperative findings. ${ }^{18}$ Further trials are necessary to evaluate the effects of different parameters and possible predictors in the treatment of OCD and depression. These trials require both a high level of ethics and excellent methodological designs, and they may benefit from larger studies, genetic studies, and imaging studies to elucidate the mechanisms.

\section{Acknowledgments}

This study was supported by a grant from Buddhist Tzu-Chi General Hospital to Dr Hsin-Chi Tsai (Grant No: TCRD95-29). Portions of this work were presented in poster form at the CINP (The International College of Neuropsychopharmacology) World Congress, Hong Kong, June 6-10, 2010.

\section{Disclosure}

The authors report no conflict of interest concerning the materials or methods used in this study or the findings specified in this paper.

\section{References}

1. Stein DJ. Obsessive-compulsive disorder. Lancet. 2002;360(9330): 397-405.

2. Kessler RC, Berglund P, Demler O, Jin R, Merikangas KR, Walters EE. Lifetime prevalence and age-of-onset distributions of DSM-IV disorders in the National Comorbidity Survey Replication. Arch Gen Psychiatry. 2005;62(6):593-602.

3. Pallanti S, Quercioli L. Treatment-refractory obsessive-compulsive disorder: methodological issues, operational definitions and therapeutic lines. Prog Neuropsychopharmacol Biol Psychiatry. 2006;30(3): 400-412.

4. Krack P, Hariz MI, Baunez C, Guridi J, Obeso JA. Deep brain stimulation: from neurology to psychiatry? Trends Neurosci. 2010;33(10):474-484.

5. Abelson JL, Curtis GC, Sagher O, et al. Deep brain stimulation for refractory obsessive-compulsive disorder. Biol Psychiatry. 2005;57(5): $510-516$.

6. Nuttin BJ, Gabriels LA, Cosyns PR, et al. Long-term electrical capsular stimulation in patients with obsessive-compulsive disorder. Neurosurgery. 2003;52(6):1263-1272; discussion 1272-1264.

7. Gabriels L, Cosyns P, Nuttin B, Demeulemeester H, Gybels J. Deep brain stimulation for treatment-refractory obsessive-compulsive disorder: psychopathological and neuropsychological outcome in three cases. Acta Psychiatr Scand. 2003;107(4):275-282.

8. Goodman WK, Foote KD, Greenberg BD, et al. Deep brain stimulation for intractable obsessive compulsive disorder: pilot study using a blinded, staggered-onset design. Biol Psychiatry. 67(6):535-542.

9. Mallet L, Polosan M, Jaafari N, et al. Subthalamic nucleus stimulation in severe obsessive-compulsive disorder. $N$ Engl J Med. 2008;359(20): 2121-2134.
10. Huff W, Lenartz D, Schormann M, et al. Unilateral deep brain stimulation of the nucleus accumbens in patients with treatment-resistant obsessive-compulsive disorder: outcomes after one year. Clin Neurol Neurosurg. 2010;112(2):137-143.

11. Greenberg BD, Malone DA, Friehs GM, et al. Three-year outcomes in deep brain stimulation for highly resistant obsessive-compulsive disorder. Neuropsychopharmacology. 2006;31(11):2384-2393.

12. Anderson D, Ahmed A. Treatment of patients with intractable obsessivecompulsive disorder with anterior capsular stimulation. Case report. J Neurosurg. 2003;98(5):1104-1108.

13. Aouizerate B, Cuny E, Martin-Guehl C, et al. Deep brain stimulation of the ventral caudate nucleus in the treatment of obsessive-compulsive disorder and major depression. Case report. J Neurosurg. 2004;101(4): 682-686.

14. Sturm V, Lenartz D, Koulousakis A, et al. The nucleus accumbens: a target for deep brain stimulation in obsessive-compulsive- and anxietydisorders. J Chem Neuroanat. 2003;26(4):293-299.

15. Aouizerate B, Martin-Guehl C, Cuny E, et al. Deep brain stimulation for OCD and major depression. Am J Psychiatry. 2005;162(11):2192.

16. Kuhn J, Grundler TO, Lenartz D, Sturm V, Klosterkotter J, Huff W. Deep brain stimulation for psychiatric disorders. Dtsch Arztebl Int. 2010;107(7):105-113.

17. Greenberg BD, Gabriels LA, Malone DA Jr, et al. Deep brain stimulation of the ventral internal capsule/ventral striatum for obsessive-compulsive disorder: worldwide experience. Mol Psychiatry. 2010;15(1):64-79.

18. Haq IU, Foote KD, Goodman WG, et al. Smile and laughter induction and intraoperative predictors of response to deep brain stimulation for obsessive-compulsive disorder. Neuroimage. 2011;54 Suppl 1: $\mathrm{S} 247-\mathrm{S} 255$.

19. Pallanti S, Hollander E, Bienstock C, et al; International Treatment Refractory OCD Consortium. Treatment non-response in OCD: methodological issues and operational definitions. Int $J$ Neuropsychopharmacol. 2002;5(2):181-191.

20. Tsai HC, Chang CH, Pan JI, et al. Pilot study of deep brain stimulation in refractory obsessive-compulsive disorder ethnic Chinese patients. Psychiatry Clin Neurosci. 2012;66(4):303-312.

21. Kawakami K, Takai-Kawakami K, Tomonaga M, Suzuki J, Kusaka T, Okai T. Origins of smile and laughter: a preliminary study. Early Hum Dev. 2006;82(1):61-66.

22. Springer US, Bowers D, Goodman WK, Shapira NA, Foote KD, Okun MS. Long-term habituation of the smile response with deep brain stimulation. Neurocase. 2006;12(3):191-196.

23. Okun MS, Bowers D, Springer U, et al. What's in a "smile?" Intraoperative observations of contralateral smiles induced by deep brain stimulation. Neurocase. 2004;10(4):271-279.

24. Benabid AL, Koudsie A, Benazzouz A, et al. Deep brain stimulation for Parkinson's disease. Adv Neurol. 2001;86:405-412.

25. Baldo BA, Kelley AE. Discrete neurochemical coding of distinguishable motivational processes: insights from nucleus accumbens control of feeding. Psychopharmacology (Berl). 2007;191(3):439-459.

26. Shapira NA, Okun MS, Wint D, et al. Panic and fear induced by deep brain stimulation. J Neurol Neurosurg Psychiatry. 2006;77(3):410-412.

27. Schoenen J, Di Clemente L, Vandenheede M, et al. Hypothalamic stimulation in chronic cluster headache: a pilot study of efficacy and mode of action. Brain. 2005;128(Pt 4):940-947.

28. Franzini A, Ferroli P, Leone M, Broggi G. Stimulation of the posterior hypothalamus for treatment of chronic intractable cluster headaches: first reported series. Neurosurgery. 2003;52(5):1095-1099; discussion 1099-1101.

29. Vigneri S, Guaraldi P, Calandra-Buonaura G, et al. Switching on the deep brain stimulation: effects on cardiovascular regulation and respiration. Auton Neurosci. 2012;166(1-2):81-84.

30. Kopell BH, Greenberg BD. Anatomy and physiology of the basal ganglia: implications for DBS in psychiatry. Neurosci Biobehav Rev. 2008;32(3):408-422.

31. Schober JM, Pfaff D. The neurophysiology of sexual arousal. Best Pract Res Clin Endocrinol Metab. 2007;21(3):445-461. 
Neuropsychiatric Disease and Treatment

Dovepress

\section{Publish your work in this journal}

Neuropsychiatric Disease and Treatment is an international, peerreviewed journal of clinical therapeutics and pharmacology focusing on concise rapid reporting of clinical or pre-clinical studies on a range of neuropsychiatric and neurological disorders. This journa is indexed on PubMed Central, the 'PsycINFO' database and CAS

The manuscript management system is completely online and includes a very quick and fair peer-review system, which is all easy to use. Visit http://www.dovepress.com/testimonials.php to read real quotes from published authors.

Submit your manuscript here: http://www.dovepress.com/neuropsychiatric-disease-and-treatment-journal 